\title{
At the Crossroads of the Adipocyte and Osteoclast Differentiation Programs: Future Therapeutic Perspectives
}

\author{
Shanmugam Muruganandan ${ }^{1, * \mathbb{D}}$, Andreia M. Ionescu ${ }^{1}$ and Christopher J. Sinal ${ }^{2}$ \\ 1 Department of Developmental Biology, Harvard School of Dental Medicine, 188 Longwood Avenue, Boston, \\ MA 02115, USA; andreia_ionescu@hms.harvard.edu \\ 2 Department of Pharmacology, Dalhousie University, Halifax, NS B3H 4R2, Canada; christopher.sinal@dal.ca \\ * Correspondence: muruganandan_shanmugam@hsdm.harvard.edu; Tel.: +614-971-0412
}

Received: 18 February 2020; Accepted: 25 March 2020; Published: 26 March 2020

check for updates

\begin{abstract}
The coordinated development and function of bone-forming (osteoblasts) and bone-resorbing (osteoclasts) cells is critical for the maintenance of skeletal integrity and calcium homeostasis. An enhanced adipogenic versus osteogenic potential of bone marrow mesenchymal stem cells (MSCs) has been linked to bone loss associated with diseases such as diabetes mellitus, as well as aging and postmenopause. In addition to an inherent decrease in bone formation due to reduced osteoblast numbers, recent experimental evidence indicates that an increase in bone marrow adipocytes contributes to a disproportionate increase in osteoclast formation. Therefore, a potential strategy for therapeutic intervention in chronic bone loss disorders such as osteoporosis is to interfere with the pro-osteoclastogenic influence of marrow adipocytes. However, application of this approach is limited by the extremely complex regulatory processes in the osteoclastogenic program. For example, key regulators of osteoclastogenesis such as the receptor activator of nuclear factor-kappaB ligand (RANKL) and the soluble decoy receptor osteoprotegerin (OPG) are not only secreted by both osteoblasts and adipocytes, but are also regulated through several cytokines produced by these cell types. In this context, biologically active signaling molecules secreted from bone marrow adipocytes, such as chemerin, adiponectin, leptin, visfatin and resistin, can have a profound influence on the osteoclast differentiation program of hematopoietic stem cells (HSCs), and thus, hold therapeutic potential under disease conditions. In addition to these paracrine signals, adipogenic transcription factors including CCAAT/enhancer binding protein alpha (C/EBP $\alpha), \mathrm{C} / \mathrm{EBP}$ beta $(\mathrm{C} / \mathrm{EBP} \beta)$ and peroxisome proliferator-associated receptor gamma (PPAR $\gamma)$ are also expressed by osteoclastogenic cells. However, in contrast to MSCs, activation of these adipogenic transcription factors in HSCs promotes the differentiation of osteoclast precursors into mature osteoclasts. Herein, we discuss the molecular mechanisms that link adipogenic signaling molecules and transcription factors to the osteoclast differentiation program and highlight therapeutic strategies targeting these mechanisms for promoting bone homeostasis.
\end{abstract}

Keywords: adipocyte osteoclast cross talk ppar gamma; cebp alpha; cebp beta

\section{Introduction}

Bone is a dynamic connective tissue that continuously undergoes homeostatic remodeling throughout life via a tightly regulated balance between the resorption of old bone and the formation of new bone tissue [1-7]. Osteoblasts are the primary bone formative cell type while osteoclasts are the key resorptive cells that govern bone remodeling and maintain skeletal integrity [1,2,4-6]. A tight coupling between the formation and function of osteoblasts and osteoclasts is required to 
maintain the homeostatic balance between bone formation and resorption. Two distinct self-renewing populations of multipotent stem cells reside within bone marrow-mesenchymal stem cells (MSCs) that give rise to the mesenchymal lineages, including osteoblasts and hematopoietic stem cells (HSCs) that give rise to all blood cell types including the monocyte lineage, from which osteoclasts are derived $[3,6,8]$. Under normal conditions, coordinated bone remodeling is achieved through a complex paracrine signaling network that regulates the osteoblastogenic and osteoclastogenic programs of the respective stem cell precursors [1-8]. For example, receptor activator of nuclear factor-kappa B ligand (RANKL) is an indispensable factor for osteoclast differentiation of hematopoietic lineage cells, but is primarily produced by cells of the osteoblast lineage $[9,10]$. Furthermore, among the isoforms of RANKL produced in bone marrow, the membrane-bound form, which requires cell-to-cell contact between osteoblast precursors and HSCs for activity, is more effective than the secreted soluble forms at promoting osteoclastogenesis [11,12]. Similarly, initiation of the osteoblast developmental program is largely dependent upon signals from cells of the osteoclast lineage within the bone microenvironment [13-17]. For instance, retrograde signaling transduced by osteoclast precursors through surface-bound RANKL molecules on osteoblast precursors induces an osteoblastogenic stimulus in the osteoblast precursors [13-15]. Thus, the current literature provides experimental evidence for the existence of both osteoblast-mediated osteoclastogenic and osteoclast-mediated osteoblastogenic differentiation through the bidirectional RANKL-RANK signaling system that serves to coordinate the local development and activities of osteoblast and osteoclast precursor cells.

In addition to osteoblasts, bone marrow MSCs are also able to differentiate into adipocytes. It is well-established that the adipogenic and osteoblastogenic differentiation programs are competitively balanced such that mechanisms which promote adipogenesis actively suppress the osteoblastogenic program $[3,6,18]$. Several osteoporotic bone loss disorders associated with age, postmenopause and chronic diseases such as diabetes mellitus are characterized by an increase in bone marrow adipogenesis and reduced bone formation $[3,6,18]$. Consistent with the competitive nature of lineage allocation, adipogenic transcription factors including peroxisome proliferator-associated receptor gamma (PPAR $\gamma$ ) and CCAAT/enhancer binding protein alpha $(\mathrm{C} / \mathrm{EBP} \alpha)$ have been shown to suppress the MSC osteoblastogenic program [3,19-22]. The activities of these adipogenic transcription factors, as well as osteoblastogenic signaling pathways such as Wnt/ $\beta$-catenin are influenced by extracellular factors present within the local bone microenvironment. For example, our previous studies provide evidence for a negative regulation of the osteoblastogenic program by the adipocyte secreted signaling molecule (adipokine) chemerin. Chemerin activates the cognate receptor chemokine-like receptor 1 (CMKLR1) to suppress the bone-anabolic Wnt/ $\beta$-catenin and Notch signaling pathways in MSCs [23]. However, other adipokines such as leptin, adiponectin and omentin- 1 have been shown to stimulate osteoblast differentiation [6,24-26]. Although mixed results have been observed for adipokines, the majority of commonly occurring bone loss disorders are associated with increased numbers of bone marrow adipocytes [18]. Thus, increased bone marrow adipogenesis can adversely affect bone remodeling via a direct negative impact upon the MSC osteoblast differentiation program.

Recent studies have revealed that adipogenic transcription factors including PPAR $\gamma, \mathrm{C} / \mathrm{EBP} \alpha$ and CEBP $\beta$ are also expressed and activated in hematopoietic lineage cells during osteoclast differentiation and are critical for the lineage priming, differentiation and activity of osteoclasts [27-35]. Furthermore, several adipokines are reported to influence the osteoclastogenic program of HSCs suggesting that increased bone marrow adipogenesis could exert further detrimental effects on bone health by uncoupling osteoblast-osteoclast communication in a fashion that promotes osteoclastogenesis and bone resorption $[6,7,36-38]$. In the present review, we discuss recent progress in the understanding of the influence of adipogenic events on the osteoclast differentiation program and highlight the future therapeutic potential for targeting these pathways to promote bone regeneration in disorders of bone loss. 


\section{Regulation of Osteoclastogenesis Through the Adipogenic Program}

Until recently, studies on osteoclast recruitment, differentiation and function have focused primarily on osteoblast lineage-derived molecules such as macrophage-colony stimulating factor (MCSF), RANKL and osteoprotegerin (OPG) [9,10,39]. The intracellular osteoclastogenic pathways linked to these stimuli are mediated through distinct RANK-mediated activation of tumor necrosis factor receptor-associated factors (TRAFs) that leads to the feed forward expression and activation of nuclear factor-kappa B (NFkB), c-fos and nuclear factor of activated T cells 1 (NFATc1) in HSCs, ultimately inducing the osteoblast-dependent osteoclast differentiation [40-42]. However, several recent studies have addressed the intracellular mechanisms that are interwoven between the adipogenic and osteoclastogenic programs [27-32]. In this context, it has been reported that some of the key players known to regulate MSC adipocyte differentiation are expressed and crucial for HSC osteoclast differentiation and likewise, the major osteoclast differentiation factor RANKL is highly expressed in bone marrow adipocytes [27-34,43-46]. These findings have recently gained greater attention due to their disease relevance since the control of osteoclast differentiation under these conditions could be driven by an adipogenic program, regardless of the status of the osteoblastogenic differentiation program [46]. Conceptually, this was first demonstrated directly by studies showing that bone marrow adipocytes can induce HSC osteoclastogenesis even in the absence of osteogenic lineage cells $[44,45]$. Thus, the involvement of key adipogenic transcription factors such as $C / E B P \alpha, C / E B P \beta$ and PPAR $\gamma$ in driving HSC osteoclast differentiation, coupled with the expression of RANKL by marrow adipocytes, provide an efficacious stimulus that can uncouple osteoclastogenesis from paracrine signaling by preosteoblasts under disease conditions. Moreover, other bone marrow adipocyte-secreted molecules have also been shown to interact with their cognate receptors on HSCs to promote osteoclast differentiation. Together, these studies suggest that bone marrow adipocytes are not only a positive regulator of HSC osteoclastogenesis, but developmentally, HSCs also share an intertwined signaling system with the adipogenic program that is amenable to activation by diseases promoting bone marrow adipogenesis.

\section{Transcription Factors in the Intertwining of Adipogenesis and Osteoclastogenesis}

\subsection{PPAR $\gamma:$ The Master Adipogenic Transcription Factor}

A key finding in the field of osteoclast development was that among all the hematopoietic stem cell and progenitor populations in bone marrow, those that express PPAR $\gamma$ are specifically endowed with the ability to commit into the osteoclast lineage [29]. Using in vivo lineage tracing strategies with PPAR $\gamma$-tTA TRE-H2BGFP reporter mice, Wei et al. (2011) demonstrated that osteoclasts are derived from PPAR $\gamma$-expressing cells of the hematopoietic lineage [29]. The GFP+ PPAR $\gamma+$ but not the GFPPPAR $\gamma$ - bone marrow cells derived from the PPAR $\gamma$-tTA TRE-H2BGFP reporter mice differentiated into mature osteoclasts when cultured under osteoclastogenic conditions indicating that the osteoclastogenic precursor population lies within the PPAR $\gamma+$ bone marrow subpopulation. Further, the impact of PPAR $\gamma$-expressing hematopoietic subsets on bone homeostasis was confirmed by selective depletion of PPAR $\gamma+$ cells in mice [29]. This was achieved using a novel transgenic mouse model generated by crossing transgenic mice expressing Cre recombinase under the control of the PPAR $\gamma$ promoter driven tetracycline-controlled transactivator protein (tTA) combined with a tetracycline-responsive promoter element (TRE)-Cre transgene (PPAR $\gamma$-tTA TRE-Cre) with a second line of transgenic mice that exhibited conditional expression of diphtheria toxin (DTA) in the presence of Cre (DTA-floxed). This resulted in the selective ablation of PPAR $\gamma^{+}$progenitors, ablation of osteoclast differentiation and an osteopetrotic (abnormally dense bone) phenotype in the offspring [29]. Furthermore, specific activation of Notch in the PPAR $\gamma^{+}$progenitor cell populations by breeding the PPAR $\gamma$-tTA TRE-Cre mice with a constitutively active Notch Intracellular Domain (NICD)-floxed mice suppressed osteoclast differentiation. This is consistent with a role for Notch activation in the suppression of PPAR $\gamma$ signaling in osteoclastogenic cells [29] that is analogous to the suppression of adipogenesis in MSCs by Notch [23,47-50]. Taken 
together, these studies indicate that PPAR $\gamma$ activation can induce adverse effects on skeletal homeostasis through the combined effects of reduced bone formation due to suppression of MSC osteoblastogenesis on one hand, and exacerbated bone resorption due to increased HSC osteoclastogenesis on the other.

A similar association exists between the molecular mechanisms that regulate the expression and function of PPAR $\gamma$. For instance, several studies suggest that the class II histone deacetylase 9 (HDAC9) acts in a negative feedback loop with adipogenic transcription factors such as PPAR $\gamma$ to regulate MSC adipogenesis by repressing PPAR $\gamma$ expression in the undifferentiated state of MSCs, whereas under adipogenic conditions, the stimulation of PPAR $\gamma$ expression transrepresses HDAC9 gene expression to permit adipogenic gene expression and differentiation [23,51,52]. In parallel to a role in MSC adipogenesis, it was recently reported that HDAC9-knockout (-/-) mice exhibit low bone mass due to exacerbated osteoclast formation and bone resorption [48]. This phenotype could be rescued by transplanting bone marrow from wild-type (WT) mice to HDAC9 (-/-) mice, while transfer of bone marrow from HDAC9 (-/-) mice to WT mice induced the bone resorption phenotype in the latter [53]. This supports the view that the interplay between PPAR $\gamma$ and HDAC9 is relevant to both bone marrow osteoblastogenic and osteoclastogenic cell populations. Further, it is well-established that PPAR $\gamma$ and Wnt/ $\beta$-catenin form a negative feedback loop in MSCs such that PPAR $\gamma$ drives adipogenesis by transrepressing HDAC9, cyclin D1 and Notch expression and signaling that ultimately limits osteoblastogenic Wnt/ $\beta$-catenin signaling $[23,54]$. Parallel to MSCs, it has been reported that PPAR $\gamma$ also downregulates Wnt/ $\beta$-catenin signaling in HSCs, which in turn induces peroxisome proliferator-activated receptor-gamma coactivator-1 beta (PGC1 $\beta$ ) expression during osteoclastogenesis (Figure 1). Mechanistically, PGC1 $\beta$ exhibits dual roles in HSCs by transactivating c-fos expression which induces osteoclast differentiation and by stimulating mitochondrial biogenesis which supports osteoclast function during bone resorption (Figure 1). As such, PGC1 $\beta$ serves as a common mediator for both PPAR $\gamma$ stimulation of osteoclastogenesis and the resorptive functions of mature osteoclasts [28]. In addition, PPAR $\gamma$ also directly induces the expression of estrogen receptor-related receptor alpha $(\mathrm{ERR} \alpha)$ which coordinates with PGC1 $\beta$ to induce mitochondrial biogenesis (Figure 1) that additionally contributes to the PPAR $\gamma$-mediated activation of mature osteoclasts [28]. Consistent with this, targeted deletion of PGC1 $\beta$ in osteoclastogenic cells by breeding PGC1 $\beta$-floxed mice with Tie2cre-transgenic mice resulted in the abrogation of PPAR $\gamma$-induced bone resorption $[27,28]$. Thus, it is now clear that PPAR $\gamma$ is also an integral component of the core transcriptional machinery of HSCs (Figure 1) and activation of this transcription factor under adipogenic conditions in bone marrow can induce osteoclast differentiation and increase bone resorption in disease conditions. 


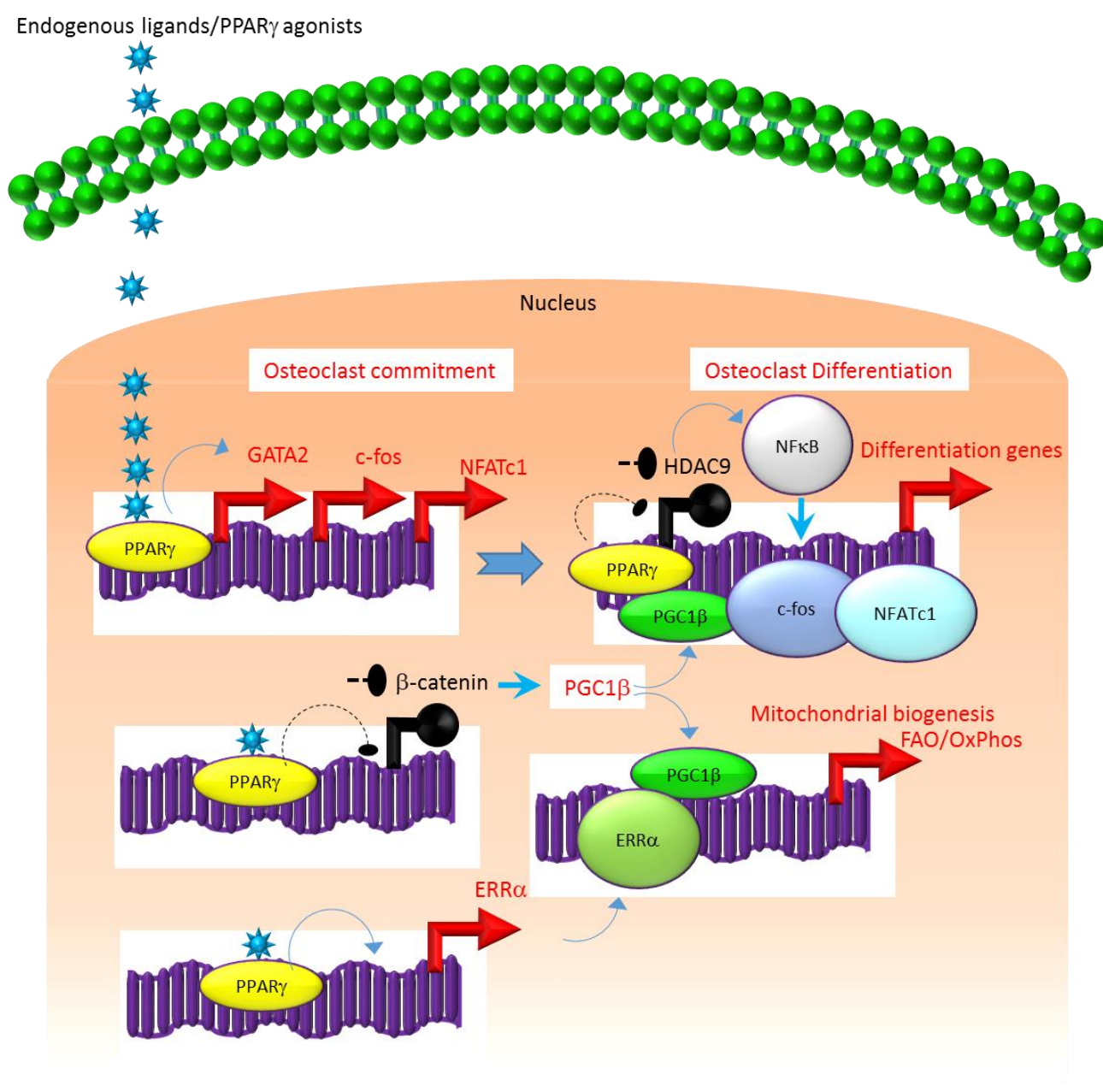

Figure 1. Regulation of osteoclastogenesis by PPAR $\gamma$. Adipogenic stimulus prevailing in bone marrow can induce osteoclastogenesis by activating PPAR $\gamma$ that in turn activates the transcription of target genes such as GATA2, c-fos, NFATC1 and ERR1 $\alpha$ that induce osteoclast differentiation in HSCs. Additionally, suppression of Wnt/ $\beta$-catenin signaling by PPAR $\gamma$ can induce PGC $1 \beta$ which can function as a transcriptional co-activator for ERR $1 \alpha$ to promote the induction of mitochondrial fatty acid $\beta$-oxidation and oxidative phosphorylation genes that are critical for inducing mitochondrial biogenesis to support osteoclast function. PGC1 $\beta$ also can serve as a transcriptional co-activator for PPAR $\gamma$ to induce target genes that stimulate osteoclast differentiation. Blue colored arrow-ended lines: stimulation/activation; Black circle-ended dash lines: inhibition. Red colored pointed arrows: transcriptional activation; Black colored closed circles: transcriptional repression.

\section{2. $C / E B P \alpha$}

Similar to PPAR $\gamma$, considerable experimental evidence also supports a role for the adipogenic transcription factor $\mathrm{C} / \mathrm{EBP} \alpha$ as a hematopoietic transcription factor $[55,56]$ that promotes the osteoclastogenic differentiation program [30-33].

Mechanistically, $\mathrm{C} / \mathrm{EBP} \alpha$ serves as an osteoclastogenic factor through its ability to bind DNA and activate the transcription of several osteoclast-specific transcription factors including NFATc1 and c-fos (Figure 2) as well as genes required for osteoclast resorptive function including cathepsin $\mathrm{K}$ (Ctsk) and osteoclast-specific vacuolar proton pump (Atp6i, also known as Tcirg1; Figure 2) that promotes osteoclast differentiation and function [31]. Promoter activity mapping and chromatin immunoprecipitation (ChIP) assays have identified cis-regulatory elements (CREs) located in the promoter regions and have identified these as direct regulatory targets of $\mathrm{C} / \mathrm{EBP} \alpha$ [31] (Figure 2). This has been linked to paracrine osteoclastogenic signaling by the observation that the ${ }^{535}{ }^{I V V Y}{ }^{538}$ 
(IVVY) motif of RANK stimulates C/EBP $\alpha$ expression, which in turn activates the expression of osteoclastogenic genes (Figure 2) and promotes osteoclast differentiation of HSCs [35]. Consistent with this, mutation of the IVVY motif blocked RANKL stimulation of C/EBP $\alpha$ expression and osteoclast differentiation of HSCs [35]. It has been reported that $\mathrm{C} / \mathrm{EBP} \alpha$ has a substantial and wide-ranging role throughout multiple phases of osteoclast development and function. For example, overexpression of $\mathrm{C} / \mathrm{EBP} \alpha$ alone was reported to be sufficient to promote osteoclast lineage commitment of HSCs even in the absence of RANKL stimulation [31,35]. Furthermore, ectopic expression of C/EBP $\alpha$ in differentiated macrophages reprogrammed the cells to fuse and convert into osteoclast-like cells with a marked induction of several osteoclast marker genes including TRAP, Ctsk, NFATc1, c-fos, MMP9, TRAF6 and RANK coincident with a downregulation of the macrophage marker F4/80 [31]. Consistent with these findings, $\mathrm{C} / \mathrm{EBP} \alpha^{+/-}$and $\mathrm{C} / \mathrm{EBP} \alpha^{-/-}$mice were reported to exhibit a gene dosage-dependent loss of osteoclast numbers and an osteopetrosis phenotype [31]. In addition to a role in osteoclast lineage commitment and maturation, $\mathrm{C} / \mathrm{EBP} \alpha$ is also critical for osteoclast function as it is essential to stimulate the extracellular acidification process and to maintain osteoclast survival during resorption [30]. Together, these studies provide evidence that $\mathrm{C} / \mathrm{EBP} \alpha$ is an osteoclastogenic transcription factor that can effectively induce osteoclast differentiation and function (Figure 2).

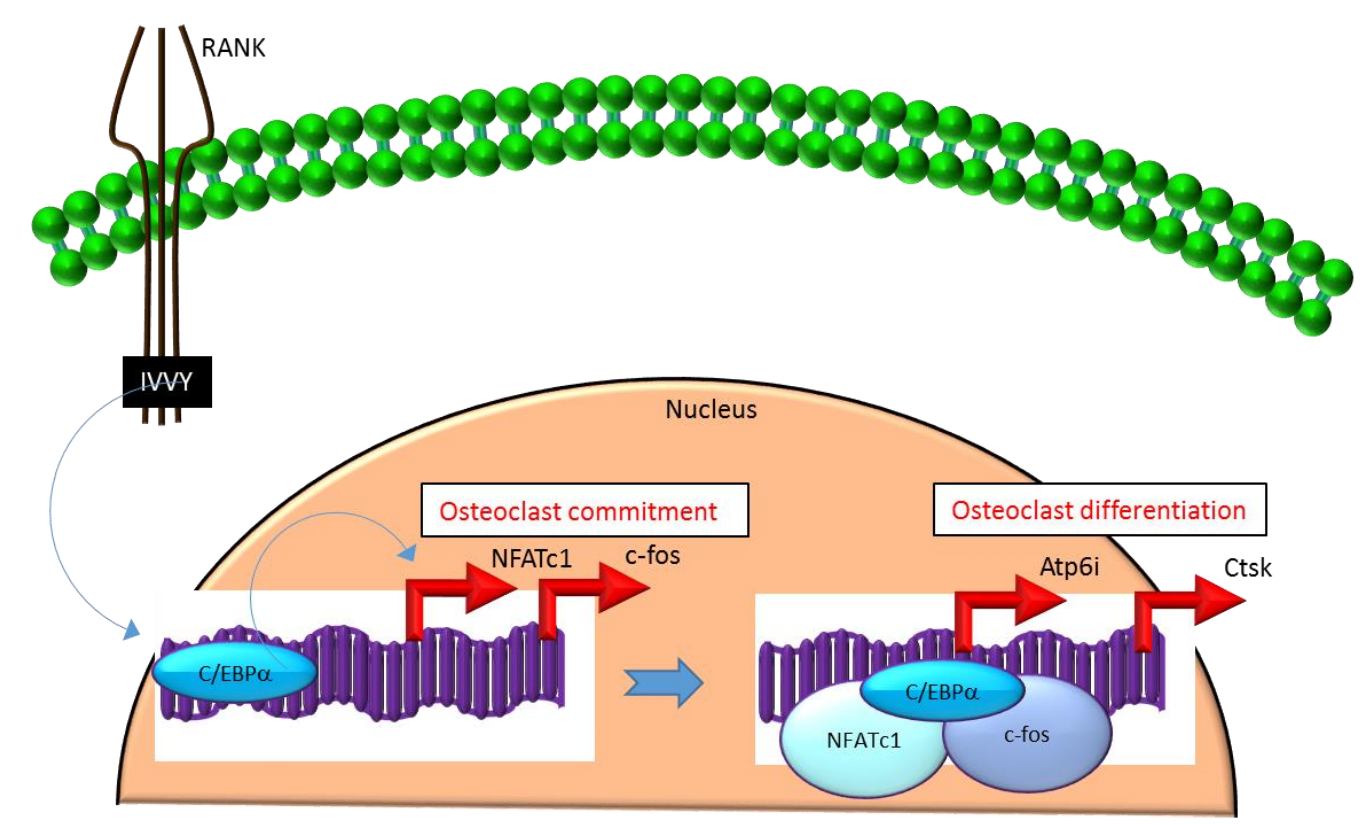

Figure 2. $\mathrm{C} / \mathrm{EBP} \alpha$ promotes lineage commitment, differentiation and function of osteoclasts. An increase in C/EBP $\alpha$ expression in HSCs is mediated through activation of IVVY motif of the cytoplasmic domain of RANK. C/EBP $\alpha$ can activate transcription of the master osteoclastogenic transcription factor NFATc1 and c-fos to promote osteoclast lineage commitment independent of the presence or absence of RANKL. In addition, $\mathrm{C} / \mathrm{EBP} \alpha$ can also function as a transcriptional co-activator for NFATc1 and c-fos to induce osteoclastogenic target genes and promote osteoclast differentiation. Blue colored arrow-ended lines: stimulation/activation. Red colored pointed arrows: transcriptional activation. 


\section{3. $C / E B P \beta$}

$\mathrm{C} / \mathrm{EBP} \beta$ is encoded by an intronless gene that directs the production of four protein isoforms-a $38 \mathrm{kDa}$ full-length C/EBP $\beta, 34 \mathrm{kDa}$ liver-enriched activating protein (LAP), $21 \mathrm{kDa}$ liver-enriched inhibitory protein (LIP), and a smaller inactive 14-kDa isoform. All of these isoforms are generated by alternative translation initiation from consecutive in-frame start codons directed under the control of the mammalian target of rapamycin kinase (mTOR) pathway $[33,34,57,58]$. The LIP isoform lacks a major portion of the transactivation domain but retains the DNA-binding domain and dimerization domain that confers its function as a dominant negative regulator of the transactivator isoforms LAP and full-length C/EBP $\beta[33,34]$. It is well-established that regulation of C/EBP $\beta$ mRNA expression and the relative levels and turnover of LIP and LAP isoforms play a major role in adipocyte differentiation [59]. For example, constitutive overexpression of C/EBP $\beta$-LIP suppresses adipogenesis, while that of $\mathrm{C} / \mathrm{EBP} \beta$-LAP promotes adipogenesis by regulating the expression of PPAR $\gamma$ in MSCs [60,61]. The balance between the expression of long transactivator isoforms (full-length or LAP) and the truncated repressor LIP is determined by the mTOR pathway that acts as a key sensor to integrate the differentiation pathways with the nutrient stimuli $[33,62,63]$. Although some reports suggest that mTOR activates LAP to induce adipogenesis, other evidence indicates that the DEP domain containing the mTOR-interacting protein (DEPTOR) strongly induces PPAR $\gamma$ and adipogenesis by inhibiting mTOR [64]. This suggests that the mechanisms by which C/EBP $\beta$ impacts adipocyte differentiation is highly complex and the nature of mTOR signaling determines the relative function of full-length/LAP versus LIP isoforms in inducing or repressing the differentiation program. Similar to the adipogenic cells, the balance between the long transactivator isoforms (full-length/LAP) and the truncated repressor LIP is also regulated by the mTOR pathway in the osteoclastogenic cells [33,34]. Moreover, the osteoclast differentiation program is influenced by the LAP to LIP ratio that determines the activation/repression of C/EBP $\beta$ target genes in HSCs [33,34]. In contrast to adipogenesis, HSC osteoclastogenesis is generally suppressed by LAP and stimulated by LIP.

Mechanistically, these actions in HSCs are mediated through the differential regulation of the downstream transcription factor Maf basic leucine zipper (bZIP) transcription factor B (MafB) $[33,34,65]$. MafB is a negative regulator of osteoclast differentiation and is a direct target gene of C/EBP $\beta$-LAP $[33,34,65]$. MafB represses the expression of several osteoclast transcription factors including NFATc1, c-fos and microphthalmia-associated transcription factor (Mitf) $[33,65]$ and thereby, inhibits osteoclast differentiation (Figure 3). Consistent with this, it has been reported that repression of MafB resulting from either targeted deletion of LAP or forced expression of LIP was sufficient to induce osteoclast differentiation in HSCs [34]. Taken together, these studies indicate that the ratio of the transactivator to repressor isoforms of $C / E B P \beta$ is a key determinant of HSC fate by linking the mTOR pathway to the osteoclast differentiation program through regulation of MafB expression (Figure 3). 


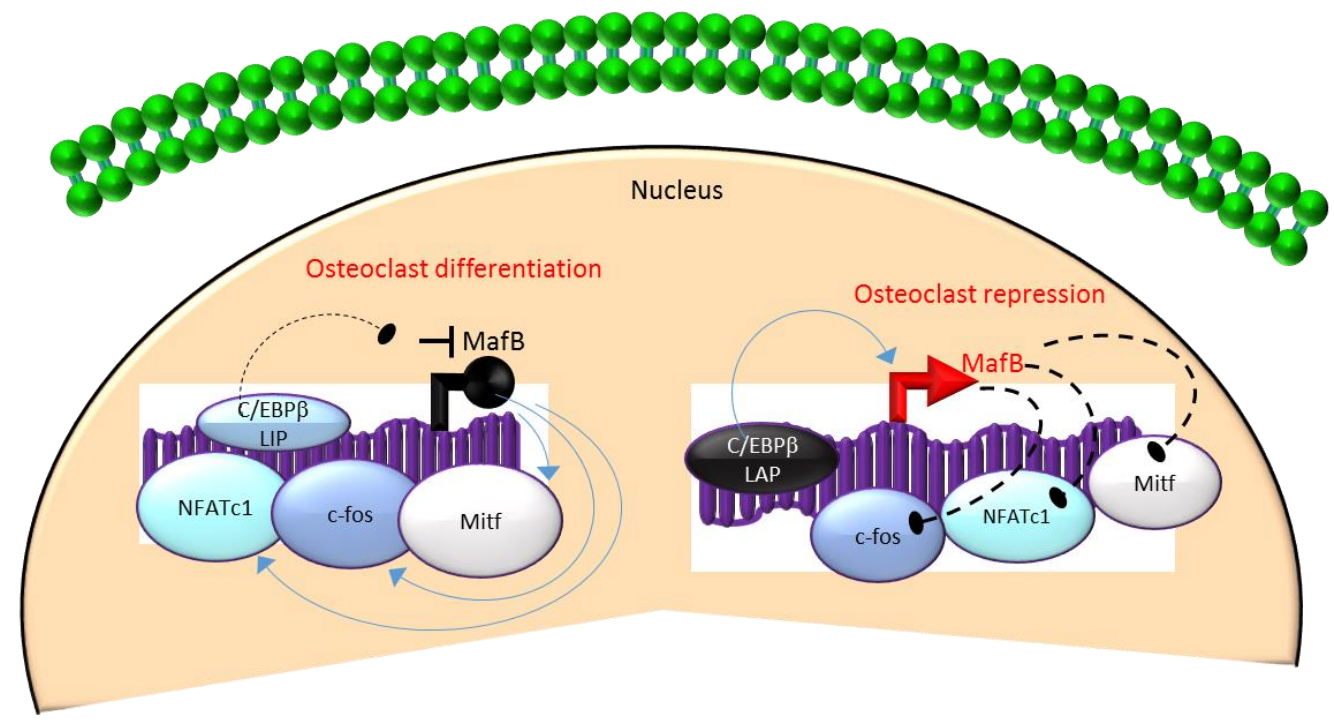

Figure 3. A negative feedback loop between $\mathrm{C} / \mathrm{EBP} \beta$ and $\mathrm{MafB}$ regulates osteoclastogenesis. $\mathrm{C} / \mathrm{EBP} \beta$ is produced as two major isoforms: C/EBP $\beta$-LAP (stimulatory) and C/EBP $\beta$-LIP (inhibitory) which activate or repress the basic region/leucine zipper transcription factor MafB, respectively. The repression of MafB by LIP induces osteoclast differentiation due to the loss of MafB-mediated repression of NAFTc1, c-fos and Mitf. In contrast, stimulation of MafB expression by LAP blocks osteoclast differentiation due to MafB-mediated repression of NAFTc1, c-fos and Mitf. Blue colored arrow-ended lines: stimulation/activation; Black circle-ended dash lines: inhibition. Red colored pointed arrows: transcriptional activation; Black colored closed circle: transcriptional repression.

\section{Bone Marrow Adipose Tissue (BMAT)-Secreted Molecules Regulating Osteoclast Differentiation}

Accumulating evidence supports a major role for BMAT-secreted molecules in influencing the osteoclast differentiation program $[6,36,37,46,66,67]$. This is likely to be tissue-specific (to BMAT) since the major osteoclastogenic signal RANKL is reported to be highly expressed in mature bone marrow adipocytes but not in mature adipocytes at other sites such as peripheral fat depots [46]. This was demonstrated most convincingly with conditional deletion of a floxed parathyroid hormone/parathyroid hormone-related peptide receptor (PTH1R) gene through bone marrow MSC-specific Cre recombinase expression driven by paired-class homeobox transcription factor 1 (Prx1) [46]. The selective ablation of MSC PTH1R signaling resulted in increased BMAT, increased osteoclast differentiation and bone resorption as well as a low bone mass phenotype [46]. Interestingly, BMAT was determined to be the source of the elevated RANKL linked to increased bone resorption in this mouse model suggesting a major role for bone marrow adipocytes in promoting bone resorption during disease conditions [46]. These studies further suggest that in addition to the interplay of adipogenic transcription factors with the osteoclastogenic program, bone marrow adipocytes are a major source of RANKL that drives osteoclast differentiation and bone resorption under disease conditions.

In addition to RANKL, adipokines such as chemerin, resistin, visfatin, leptin, adiponectin and omentin-1, lipids and fatty acids have been shown to influence the osteoclast differentiation program. For example, our previous studies reported that chemerin [66,67] signals through the cognate receptor CMKLR1 in HSCs to induce their differentiation into mature osteoclasts [36]. Chemerin/CMKLR1 signaling was found to regulate expression of the key osteoclast transcription factor NFATc1 and thereby, induce osteoclast differentiation and matrix resorption [36]. An experimental approach using chemerin neutralization identified a near complete blockade of osteoclast differentiation in HSCs suggesting that a basal level of chemerin is required for HSC osteoclastogenesis [36]. Moreover, it is noteworthy that the chemerin neutralization approach also resulted in a blockade of adipocyte differentiation of bone marrow MSCs [66], and thereby could exert a positive influence on the 
osteoblastogenic program of MSCs [23,68]. Therefore, approaches to block chemerin signaling or neutralize the chemerin protein in patients' bone marrow may have therapeutic value for treating disorders of bone loss due to combined benefits resulting from inhibition of bone resorption due to blockade of HSC osteoclastogenesis and enhanced bone formation due to stimulation of MSC osteoblastogenesis. Similar to chemerin, resistin has been reported to exhibit a positive influence on the osteoclast development through a mechanism involving activation of nuclear factor of kappa $B$ (NFkB) signaling [37]. The adipokine visfatin, also known as nicotinamide phosphoribosyltransferase (Nampt) or pre-B-cell colony-enhancing factor is essential for the biosynthesis of the coenzyme nicotinamide adenine dinucleotide (NAD) [69]. In contrast to chemerin, some reports suggest an inhibitory role for visfatin in the osteoclast differentiation program $[69,70]$. For example, Baek et al. (2017) reported that visfatin inhibited the phosphorylation of various early signal transducers, including c-Jun N-terminal kinase, Akt, glycogen synthase kinase-3 $\beta$, Bruton's tyrosine kinase and phospholipase $C \gamma$-2 to suppress RANKL-induced osteoclastogenesis [70]. However, other studies using FK866, an inhibitor of visfatin, have demonstrated that visfatin is also required for the recruitment of osteoclasts to the bone surface [66]. Similar to visfatin, other adipokines such as leptin, adiponectin and omentin-1 also negatively impact bone resorption by affecting the osteoclast differentiation program $[6,7,71]$. In addition to direct actions on HSCs, adipokines such as leptin and omentin-1 can also modulate osteoclast differentiation indirectly by acting on MSCs to alter their production of RANKL and osteoprotegerin (OPG), a neutralizer of RANKL, thereby modifying the net stimulus for osteoclastogenesis in HSCs [6,72-74].

\section{Future Perspective for Biomarkers and Therapeutic Targets}

A primary goal in the field of musculoskeletal research is to identify reliable therapeutic targets to prevent the onset and progression of skeletal pathologies associated with bone loss. There is currently no validated biomarker for predicting the early stages of bone-loss disorders. Several promising candidates have been investigated including carboxy-terminal crosslinking telopeptide of type I collagen, a bone resorption marker, and procollagen type I N propeptide, a marker for bone formation in osteoporotic serum [75]. Serum levels of osteoclast-derived protein cathepsin K have also been examined as a candidate biomarker [75]. However, several physiological conditions and many disease states can modify the levels of bone turnover markers and thus, render them neither fully specific nor sufficiently sensitive for their use as an early stage marker [76]. In addition, there is presently no reliable candidate for the application of biomarkers to map treatment effects. In order to improve therapeutic outcomes, the identification of potential biomarkers and the underlying mechanisms are urgently required. Recently, bone marrow fat analysis has attracted attention as a diagnostic test for the early diagnosis of chronic diseases such as osteoporosis based upon the generally accepted inverse relationship between bone marrow fat and bone health. Consistent with this, some studies have successfully used bone marrow fat analyses as a novel imaging biomarker in the clinical diagnosis of postmenopausal fragility fractures [77]. Both the amount of and nature (level of fat unsaturation) of bone marrow fat were found to reliably identify differences between fracture and nonfracture patients [77]. Although promising, analyses using such imaging techniques are limited to a single skeletal region (commonly a segment of the lumbar spine) that may not represent the state of disease in the entire skeleton [77]. Since both vertebral and peripheral fractures are common after menopause transition or with diabetes mellitus, serum biomarkers may prove to provide a more reliable representation of the entire skeleton than the narrow analyses of a limited bone segment. In this regard, bone marrow adipose tissue-secreted molecules such as adipokines (including chemerin, visfatin, omentin, adiponectin and resistin), fatty acids, extracellular vesicles and other BMAT-derived cytokines such as RANKL are potential biomarkers for the diagnosis and treatment of osteoporosis and related disorders. However, the complex interplay between adipogenic and osteogenic factors, production of these molecules by both peripheral white adipose tissue and bone marrow adipocytes as well as the context-specific relationship to bone homeostasis, highlight the need for further investigation 
into the assessment of the clinical utility of adipokines as diagnostic markers and/or therapeutic targets for drug development. In this regard, some experimental and clinical studies have reported paradoxical results or inconsistent findings regarding the relationship between the bone marrow fat and bone loss diseases [78,79]. For example, some animal models such as the WBB6F1/J-KitW/W-v mice with loss-of-function mutations on c-kit gene [80] and 11beta-hydroxysteroid dehydrogenase type 1-knockout mice [81] exhibit bone loss without the expected increase in marrow adiposity. These contradictory findings suggest that the correlation between marrow adiposity and bone loss in diseases is context-dependent and varies depending upon the stimulus that drives the bone loss. Therefore, it is essential that these factors are considered in order to provide balanced insights into the mechanisms of osteoporosis and related bone loss disorders.

Clinical evidence shows that the currently available antiresorptives such as bisphosphonates and denosumab, and anabolics such as teriparatide, reduce vertebral, nonvertebral and hip fractures in postmenopausal women [82]. However, there is also clear clinical evidence of alarming adverse effects such as atypical subtrochanteric fractures, osteonecrosis of the jaw, increased risk for the development of cardiovascular diseases (atrial fibrillation and myocardial infarction), upper gastrointestinal problems, hypocalcemia, myalgia, cramp and limb pain with the use of antiresorptives [82]. Similarly, the use of teriparatide is associated with several untoward effects including upper gastrointestinal symptoms, hypercalcemia, renal side effects and hypercalciuria [82]. Moreover, the primary therapeutic benefit of reduced fracture risk in high-risk patients requires long-term treatment even with the most commonly used first-line bisphosphonate drugs [82]. Thus, furthering our fundamental understanding of disease mechanisms is essential to develop superior therapeutic applications. In this regard, recent studies identified marrow adipose tissue accumulation as the primary factor driving the early steps of bone marrow niche dysfunction, impaired bone tissue renewal and repair [83]. Studies such as these have stimulated renewed interest in examining the link between marrow fat and bone loss and have highlighted this as an exciting area of research to identify novel approaches for osteoporosis disease management both from a diagnostic and therapeutic perspective.

In addition to the relationship between bone loss and marrow fat during disease manifestation, similar evidence exists for a relationship for the treatment of osteoporosis with most of the currently available therapies including antiresorptives and anabolics. In this regard, a number of antiresorptives and anabolic drugs have been reported to increase bone mass in parallel with a reduction of bone marrow fat [84-87]. Indeed, bisphosphonates that reduce bone loss by specifically binding to hydroxyapatite of bone and thus interfering with osteoclast function were also reported to decrease the amount of marrow fat during the course of therapy $[84,85]$. These findings also suggest that osteoclastogenic pathways may also exert a positive influence on adipocyte programming. Similarly, anabolic agents that directly promote osteoblastogenesis, suppress osteoblast apoptosis and thereby enhance bone formation, are also reported to reduce marrow fat accumulation in patients undergoing therapy [86,87]. Notably, this suppression of adipogenesis was found to be restricted to the bone marrow adipose tissue without impacting other white adipose tissue depots [86,87]. This further supports the regulation of bone mass through the cellular triad of osteoclast/osteoblast/adipocyte interactions particular to the marrow microenvironment. Future strategies to identify mechanisms between these interconnections such as alterations in adipokine signaling and the levels of marrow fat-derived substances during disease progression and therapy, and approaches to target bone marrow adipogenic events to abrogate the abnormal osteoclast formation could be of value in the diagnosis and treatment of osteoporosis.

Author Contributions: Conceptualization, S.M., A.M.I., and C.J.S.; writing-original draft preparation, S.M.; writing-review and editing, S.M., A.M.I., and C.J.S.; funding acquisition, A.M.I. All authors have read and agreed to the published version of the manuscript.

Funding: A.M.I. and S.M. are supported by a NIAMS/NIH grant 1R01AR069671-01A1 (to A.M.I.).

Conflicts of Interest: The authors declare no conflict of interest. 


\section{References}

1. Zaidi, M. Skeletal remodeling in health and disease. Nat. Med. 2007, 13, 791-801. [CrossRef] [PubMed]

2. Iqbal, J.; Sun, L.; Zaidi, M. Coupling bone degradation to formation. Nat. Med. 2009, 15, 729-731. [CrossRef] [PubMed]

3. Muruganandan, S.; Roman, A.A.; Sinal, C.J. Adipocyte differentiation of bone marrow-derived mesenchymal stem cells: Cross talk with the osteoblastogenic program. Cell. Mol. Life Sci. 2009, 66, 236-253. [CrossRef] [PubMed]

4. Tang, Y.; Wu, X.; Lei, W.; Pang, L.; Wan, C.; Shi, Z.; Zhao, L.; Nagy, T.R.; Peng, X.; Hu, J.; et al. TGF-beta1-induced migration of bone mesenchymal stem cells couples bone resorption with formation. Nat. Med. 2009, 15, 757-765. [CrossRef] [PubMed]

5. Nakashima, T.; Hayashi, M.; Fukunaga, T.; Kurata, K.; Oh-hora, M.; Feng, J.Q.; Bonewald, L.F.; Kodama, T.; Wutz, A.; Wagner, E.F.; et al. Evidence for osteocyte regulation of bone homeostasis through RANKL expression. Nat. Med. 2011, 17, 1231-1234. [CrossRef]

6. Muruganandan, S.; Sinal, C.J. The impact of bone marrow adipocytes on osteoblast and osteoclast differentiation. IUBMB Life 2014, 66, 147-155. [CrossRef]

7. Muruganandan, S.; Govindarajan, R.; Sinal, C.J. Bone marrow adipose tissue and skeletal health. Curr. Osteoporos. Rep. 2018, 16, 434-442. [CrossRef]

8. Fierro, F.A.; Nolta, J.A.; Adamopoulos, I.E. Concise review: Stem cells in osteoimmunology. Stem Cells 2017, 35, 1461-1467. [CrossRef]

9. Chen, X.; Wang, Z.; Duan, N.; Zhu, G.; Schwarz, E.M.; Xie, C. Osteoblast-osteoclast interactions. Connect Tissue Res. 2018, 59, 99-107. [CrossRef]

10. Boyce, B.F.; Xing, L. Biology of RANK, RANKL, and osteoprotegerin. Arthritis Res. Ther. 2007, 9 (Suppl. 1), S1. [CrossRef]

11. Xiong, J.; Cawley, K.; Piemontese, M.; Fujiwara, Y.; Zhao, H.; Goellner, J.J.; O’Brien, C.A. Soluble RANKL contributes to osteoclast formation in adult mice but not ovariectomy-induced bone loss. Nat. Commun. 2018, 9, 2909. [CrossRef] [PubMed]

12. Honma, M.; Ikebuchi, Y.; Kariya, Y.; Hayashi, M.; Hayashi, N.; Aoki, S.; Suzuki, H. RANKL subcellular trafficking and regulatory mechanisms in osteocytes. J. Bone Miner. Res. 2013, 28, 1936-1949. [CrossRef]

13. Ikebuchi, Y.; Aoki, S.; Honma, M.; Hayashi, M.; Sugamori, Y.; Khan, M.; Kariya, Y.; Kato, G.; Tabata, Y.; Penninger, J.M.; et al. Coupling of bone resorption and formation by RANKL reverse signalling. Nature 2018, 561, 195-200. [CrossRef] [PubMed]

14. Cao, X. RANKL-RANK signaling regulates osteoblast differentiation and bone formation. Bone Res. 2018, 6, 35. [CrossRef] [PubMed]

15. Zhang, S.; Wang, X.; Li, G.; Chong, Y.; Zhang, J.; Guo, X.; Li, B.; Bi, Z. Osteoclast regulation of osteoblasts via RANKRANKL reverse signal transduction in vitro. Mol. Med. Rep. 2017, 16, 3994-4000. [CrossRef] [PubMed]

16. Weivoda, M.M.; Ruan, M.; Pederson, L.; Hachfeld, C.; Davey, R.A.; Zajac, J.D.; Westendorf, J.J.; Khosla, S.; Oursler, M.J. Osteoclast TGF-beta receptor signaling induces Wnt1 secretion and couples bone resorption to bone formation. J. Bone Miner. Res. 2016, 31, 76-85. [CrossRef]

17. Tamma, R.; Zallone, A. Osteoblast and osteoclast crosstalks: From OAF to Ephrin. Inflamm. Allergy Drug Targets 2012, 11, 196-200. [CrossRef]

18. Chen, Q.; Shou, P.; Zheng, C.; Jiang, M.; Cao, G.; Yang, Q.; Cao, J.; Xie, N.; Velletri, T.; Zhang, X.; et al. Fate decision of mesenchymal stem cells: Adipocytes or osteoblasts? Cell Death Differ. 2016, 23, 1128-1139. [CrossRef]

19. Li, J.; Zhang, N.; Huang, X.; Xu, J.; Fernandes, J.C.; Dai, K.; Zhang, X. Dexamethasone shifts bone marrow stromal cells from osteoblasts to adipocytes by C/EBPalpha promoter methylation. Cell Death Dis. 2013, 4, e832. [CrossRef]

20. Fan, Q.; Tang, T.; Zhang, X.; Dai, K. The role of CCAAT/enhancer binding protein (C/EBP)-alpha in osteogenesis of C3H10T1/2 cells induced by BMP-2. J. Cell. Mol. Med. 2009, 13, 2489-2505. [CrossRef]

21. Sun, H.; Kim, J.K.; Mortensen, R.; Mutyaba, L.P.; Hankenson, K.D.; Krebsbach, P.H. Osteoblast-targeted suppression of PPARgamma increases osteogenesis through activation of mTOR signaling. Stem Cells 2013, 31, 2183-2192. [CrossRef] 
22. Akune, T.; Ohba, S.; Kamekura, S.; Yamaguchi, M.; Chung, U.I.; Kubota, N.; Terauchi, Y.; Harada, Y.; Azuma, Y.; Nakamura, K.; et al. PPARgamma insufficiency enhances osteogenesis through osteoblast formation from bone marrow progenitors. J. Clin. Investig. 2004, 113, 846-855. [CrossRef]

23. Muruganandan, S.; Govindarajan, R.; McMullen, N.M.; Sinal, C.J. Chemokine-Like Receptor 1 Is a Novel Wnt Target Gene that Regulates Mesenchymal Stem Cell Differentiation. Stem Cells 2017, 35, 711-724. [CrossRef]

24. Astudillo, P.; Rios, S.; Pastenes, L.; Pino, A.M.; Rodriguez, J.P. Increased adipogenesis of osteoporotic human-mesenchymal stem cells (MSCs) characterizes by impaired leptin action. J. Cell. Biochem. 2008, 103, 1054-1065. [CrossRef]

25. Lee, H.W.; Kim, S.Y.; Kim, A.Y.; Lee, E.J.; Choi, J.Y.; Kim, J.B. Adiponectin stimulates osteoblast differentiation through induction of COX2 in mesenchymal progenitor cells. Stem Cells 2009, 27, 2254-2262. [CrossRef]

26. Wu, S.S.; Liang, Q.H.; Liu, Y.; Cui, R.R.; Yuan, L.Q.; Liao, E.Y. Omentin-1 Stimulates Human Osteoblast Proliferation through PI3K/Akt Signal Pathway. Int. J. Endocrinol. 2013, 2013, 368970. [CrossRef]

27. Wan, Y.; Chong, L.W.; Evans, R.M. PPAR-gamma regulates osteoclastogenesis in mice. Nat. Med. 2007, 13, 1496-1503. [CrossRef]

28. Wei, W.; Wang, X.; Yang, M.; Smith, L.C.; Dechow, P.C.; Sonoda, J.; Evans, R.M.; Wan, Y. PGC1beta mediates PPARgamma activation of osteoclastogenesis and rosiglitazone-induced bone loss. Cell Metab. 2010, 11, 503-516. [CrossRef]

29. Wei, W.; Zeve, D.; Wang, X.; Du, Y.; Tang, W.; Dechow, P.C.; Graff, J.M.; Wan, Y. Osteoclast progenitors reside in the peroxisome proliferator-activated receptor gamma-expressing bone marrow cell population. Mol. Cell. Biol. 2011, 31, 4692-4705. [CrossRef]

30. Jules, J.; Chen, W.; Feng, X.; Li, Y.P. CCAAT/Enhancer-binding protein alpha (C/EBPalpha) is important for osteoclast differentiation and activity. J. Biol. Chem. 2016, 291, 16390-16403. [CrossRef]

31. Chen, W.; Zhu, G.; Hao, L.; Wu, M.; Ci, H.; Li, Y.P. C/EBPalpha regulates osteoclast lineage commitment. Proc. Natl. Acad. Sci. USA 2013, 110, 7294-7299. [CrossRef] [PubMed]

32. Chen, W.; Zhu, G.; Tang, J.; Zhou, H.D.; Li, Y.P. C/ebpalpha controls osteoclast terminal differentiation, activation, function, and postnatal bone homeostasis through direct regulation of Nfatc1. J. Pathol. 2018, 244, 271-282. [CrossRef] [PubMed]

33. Smink, J.J.; Leutz, A. Rapamycin and the transcription factor C/EBPbeta as a switch in osteoclast differentiation: Implications for lytic bone diseases. J. Mol. Med. 2010, 88, 227-233. [CrossRef] [PubMed]

34. Smink, J.J.; Begay, V.; Schoenmaker, T.; Sterneck, E.; de Vries, T.J.; Leutz, A. Transcription factor C/EBPbeta isoform ratio regulates osteoclastogenesis through MafB. EMBO J. 2009, 28, 1769-1781. [CrossRef]

35. Jules, J.; Chen, W.; Feng, X.; Li, Y.P. C/EBPalpha transcription factor is regulated by the RANK cytoplasmic (535)IVVY(538) motif and stimulates osteoclastogenesis more strongly than c-Fos. J. Biol. Chem. 2018, 293, 1480-1492. [CrossRef]

36. Muruganandan, S.; Dranse, H.J.; Rourke, J.L.; McMullen, N.M.; Sinal, C.J. Chemerin neutralization blocks hematopoietic stem cell osteoclastogenesis. Stem Cells 2013, 31, 2172-2182. [CrossRef]

37. Thommesen, L.; Stunes, A.K.; Monjo, M.; Grosvik, K.; Tamburstuen, M.V.; Kjobli, E.; Lyngstadaas, S.P.; Reseland, J.E.; Syversen, U. Expression and regulation of resistin in osteoblasts and osteoclasts indicate a role in bone metabolism. J. Cell. Biochem. 2006, 99, 824-834. [CrossRef]

38. Tu, Q.; Zhang, J.; Dong, L.Q.; Saunders, E.; Luo, E.; Tang, J.; Chen, J. Adiponectin inhibits osteoclastogenesis and bone resorption via APPL1-mediated suppression of Akt1. J. Biol. Chem. 2011, 286, 12542-12553. [CrossRef]

39. Khosla, S. Minireview: The OPG/RANKL/RANK system. Endocrinology 2001, 142, 5050-5055. [CrossRef]

40. Gravallese, E.M.; Galson, D.L.; Goldring, S.R.; Auron, P.E. The role of TNF-receptor family members and other TRAF-dependent receptors in bone resorption. Arthritis Res. 2001, 3, 6-12. [CrossRef]

41. Takayanagi, H. Osteoimmunology: Shared mechanisms and crosstalk between the immune and bone systems. Nat. Rev. Immunol. 2007, 7, 292-304. [CrossRef]

42. Takayanagi, H.; Kim, S.; Koga, T.; Nishina, H.; Isshiki, M.; Yoshida, H.; Saiura, A.; Isobe, M.; Yokochi, T.; Inoue, J.; et al. Induction and activation of the transcription factor NFATc1 (NFAT2) integrate RANKL signaling in terminal differentiation of osteoclasts. Dev. Cell 2002, 3, 889-901. [CrossRef]

43. Takeshita, S.; Fumoto, T.; Naoe, Y.; Ikeda, K. Age-related marrow adipogenesis is linked to increased expression of RANKL. J. Biol. Chem. 2014, 289, 16699-16710. [CrossRef] 
44. Goto, H.; Hozumi, A.; Osaki, M.; Fukushima, T.; Sakamoto, K.; Yonekura, A.; Tomita, M.; Furukawa, K.; Shindo, H.; Baba, H. Primary human bone marrow adipocytes support TNF-alpha-induced osteoclast differentiation and function through RANKL expression. Cytokine 2011, 56, 662-668. [CrossRef]

45. Goto, H.; Osaki, M.; Fukushima, T.; Sakamoto, K.; Hozumi, A.; Baba, H.; Shindo, H. Human bone marrow adipocytes support dexamethasone-induced osteoclast differentiation and function through RANKL expression. Biomed. Res. 2011, 32, 37-44. [CrossRef]

46. Fan, Y.; Hanai, J.I.; Le, P.T.; Bi, R.; Maridas, D.; DeMambro, V.; Figueroa, C.A.; Kir, S.; Zhou, X.; Mannstadt, M.; et al. Parathyroid hormone directs bone marrow mesenchymal cell fate. Cell Metab. 2017, 25, 661-672. [CrossRef]

47. Song, B.Q.; Chi, Y.; Li, X.; Du, W.J.; Han, Z.B.; Tian, J.J.; Li, J.J.; Chen, F.; Wu, H.H.; Han, L.X.; et al. Inhibition of notch signaling promotes the adipogenic differentiation of mesenchymal stem cells through autophagy activation and PTEN-PI3K/AKT/mTOR pathway. Cell. Physiol. Biochem. 2015, 36, 1991-2002. [CrossRef]

48. Osathanon, T.; Subbalekha, K.; Sastravaha, P.; Pavasant, P. Notch signalling inhibits the adipogenic differentiation of single-cell-derived mesenchymal stem cell clones isolated from human adipose tissue. Cell Biol. Int. 2012, 36, 1161-1170. [CrossRef]

49. Ugarte, F.; Ryser, M.; Thieme, S.; Fierro, F.A.; Navratiel, K.; Bornhauser, M.; Brenner, S. Notch signaling enhances osteogenic differentiation while inhibiting adipogenesis in primary human bone marrow stromal cells. Exp. Hematol. 2009, 37, 867-875. [CrossRef]

50. Huang, Y.; Yang, X.; Wu, Y.; Jing, W.; Cai, X.; Tang, W.; Liu, L.; Liu, Y.; Grottkau, B.E.; Lin, Y. Gamma-secretase inhibitor induces adipogenesis of adipose-derived stem cells by regulation of Notch and PPAR-gamma. Cell Prolif. 2010, 43, 147-156. [CrossRef]

51. Chatterjee, T.K.; Idelman, G.; Blanco, V.; Blomkalns, A.L.; Piegore, M.G.; Weintraub, D.S.; Kumar, S.; Rajsheker, S.; Manka, D.; Rudich, S.M.; et al. Histone deacetylase 9 is a negative regulator of adipogenic differentiation. J. Biol. Chem. 2011, 286, 27836-27847. [CrossRef] [PubMed]

52. Cohen, R.N. Nuclear receptor corepressors and PPARgamma. Nucl. Recept. Signal. 2006, 4, e003. [CrossRef] [PubMed]

53. Jin, Z.; Wei, W.; Huynh, H.; Wan, Y. HDAC9 Inhibits Osteoclastogenesis via Mutual Suppression of PPARgamma/RANKL Signaling. Mol. Endocrinol. 2015, 29, 730-738. [CrossRef] [PubMed]

54. Takada, I.; Kouzmenko, A.P.; Kato, S. Wnt and PPARgamma signaling in osteoblastogenesis and adipogenesis. Nat. Rev. Rheumatol. 2009, 5, 442-447. [CrossRef]

55. Suh, H.C.; Gooya, J.; Renn, K.; Friedman, A.D.; Johnson, P.F.; Keller, J.R. C/EBPalpha determines hematopoietic cell fate in multipotential progenitor cells by inhibiting erythroid differentiation and inducing myeloid differentiation. Blood 2006, 107, 4308-4316. [CrossRef]

56. Hasemann, M.S.; Lauridsen, F.K.; Waage, J.; Jakobsen, J.S.; Frank, A.K.; Schuster, M.B.; Rapin, N.; Bagger, F.O.; Hoppe, P.S.; Schroeder, T.; et al. C/EBPalpha is required for long-term self-renewal and lineage priming of hematopoietic stem cells and for the maintenance of epigenetic configurations in multipotent progenitors. PLoS Genet. 2014, 10, e1004079. [CrossRef]

57. Huber, R.; Pietsch, D.; Panterodt, T.; Brand, K. Regulation of C/EBPbeta and resulting functions in cells of the monocytic lineage. Cell Signal. 2012, 24, 1287-1296. [CrossRef]

58. An, M.R.; Hsieh, C.C.; Reisner, P.D.; Rabek, J.P.; Scott, S.G.; Kuninger, D.T.; Papaconstantinou, J. Evidence for posttranscriptional regulation of C/EBPalpha and C/EBPbeta isoform expression during the lipopolysaccharide-mediated acute-phase response. Mol. Cell. Biol. 1996, 16, 2295-2306. [CrossRef]

59. Cao, Z.; Umek, R.M.; McKnight, S.L. Regulated expression of three C/EBP isoforms during adipose conversion of 3T3-L1 cells. Genes Dev. 1991, 5, 1538-1552. [CrossRef]

60. Lechner, S.; Mitterberger, M.C.; Mattesich, M.; Zwerschke, W. Role of C/EBPbeta-LAP and C/EBPbeta-LIP in early adipogenic differentiation of human white adipose-derived progenitors and at later stages in immature adipocytes. Differentiation 2013, 85, 20-31. [CrossRef]

61. Hamm, J.K.; Park, B.H.; Farmer, S.R. A role for C/EBPbeta in regulating peroxisome proliferator-activated receptor gamma activity during adipogenesis in 3T3-L1 preadipocytes. J. Biol. Chem. 2001, 276, 18464-18471. [CrossRef] [PubMed]

62. Zidek, L.M.; Ackermann, T.; Hartleben, G.; Eichwald, S.; Kortman, G.; Kiehntopf, M.; Leutz, A.; Sonenberg, N.; Wang, Z.Q.; von Maltzahn, J.; et al. Deficiency in mTORC1-controlled C/EBPbeta-mRNA translation improves metabolic health in mice. EMBO Rep. 2015, 16, 1022-1036. [CrossRef] [PubMed] 
63. Kim, J.E.; Chen, J. Regulation of peroxisome proliferator-activated receptor-gamma activity by mammalian target of rapamycin and amino acids in adipogenesis. Diabetes 2004, 53, 2748-2756. [CrossRef] [PubMed]

64. Laplante, M.; Horvat, S.; Festuccia, W.T.; Birsoy, K.; Prevorsek, Z.; Efeyan, A.; Sabatini, D.M. DEPTOR cell-autonomously promotes adipogenesis, and its expression is associated with obesity. Cell Metab. 2012, 16, 202-212. [CrossRef] [PubMed]

65. Kim, K.; Kim, J.H.; Lee, J.; Jin, H.M.; Kook, H.; Kim, K.K.; Lee, S.Y.; Kim, N. MafB negatively regulates RANKL-mediated osteoclast differentiation. Blood 2007, 109, 3253-3259. [CrossRef] [PubMed]

66. Muruganandan, S.; Parlee, S.D.; Rourke, J.L.; Ernst, M.C.; Goralski, K.B.; Sinal, C.J. Chemerin, a novel peroxisome proliferator-activated receptor gamma (PPARgamma) target gene that promotes mesenchymal stem cell adipogenesis. J. Biol. Chem. 2011, 286, 23982-23995. [CrossRef] [PubMed]

67. Goralski, K.B.; McCarthy, T.C.; Hanniman, E.A.; Zabel, B.A.; Butcher, E.C.; Parlee, S.D.; Muruganandan, S.; Sinal, C.J. Chemerin, a novel adipokine that regulates adipogenesis and adipocyte metabolism. J. Biol. Chem. 2007, 282, 28175-28188. [CrossRef]

68. Muruganandan, S.; Roman, A.A.; Sinal, C.J. Role of chemerin/CMKLR1 signaling in adipogenesis and osteoblastogenesis of bone marrow stem cells. J. Bone Miner. Res. 2010, 25, 222-234. [CrossRef]

69. Moschen, A.R.; Geiger, S.; Gerner, R.; Tilg, H. Pre-B cell colony enhancing factor/NAMPT/visfatin and its role in inflammation-related bone disease. Mutat. Res. 2010, 690, 95-101. [CrossRef]

70. Baek, J.M.; Ahn, S.J.; Cheon, Y.H.; Lee, M.S.; Oh, J.; Kim, J.Y. Nicotinamide phosphoribosyltransferase inhibits receptor activator of nuclear factor-kappaB ligand-induced osteoclast differentiation in vitro. Mol. Med. Rep. 2017, 15, 784-792. [CrossRef]

71. Hassan, B.; Baroukh, B.; Llorens, A.; Lesieur, J.; Ribbes, S.; Chaussain, C.; Saffar, J.L.; Gosset, M. NAMPT expression in osteoblasts controls osteoclast recruitment in alveolar bone remodeling. J. Cell. Physiol. 2018, 233, 7402-7414. [CrossRef] [PubMed]

72. Liu, Y.; Song, C.Y.; Wu, S.S.; Liang, Q.H.; Yuan, L.Q.; Liao, E.Y. Novel adipokines and bone metabolism. Int. J. Endocrinol. 2013, 2013, 895045. [CrossRef] [PubMed]

73. Xie, H.; Xie, P.L.; Luo, X.H.; Wu, X.P.; Zhou, H.D.; Tang, S.Y.; Liao, E.Y. Omentin-1 exerts bone-sparing effect in ovariectomized mice. Osteoporos. Int. 2012, 23, 1425-1436. [CrossRef] [PubMed]

74. Cheng, M.; Li, T.; Li, W.; Chen, Y.; Xu, W.; Xu, L. Leptin can promote mineralization and up-regulate RANKL mRNA expression in osteoblasts from adult female SD rats. Int. J. Clin. Exp. Pathol. 2018, 11, 1610-1619.

75. Hlaing, T.T.; Compston, J.E. Biochemical markers of bone turnover - uses and limitations. Ann. Clin. Biochem. 2014, 51 Pt 2, 189-202. [CrossRef]

76. Greenblatt, M.B.; Tsai, J.N.; Wein, M.N. Bone turnover markers in the diagnosis and monitoring of metabolic bone disease. Clin. Chem. 2017, 63, 464-474. [CrossRef]

77. Patsch, J.M.; Li, X.; Baum, T.; Yap, S.P.; Karampinos, D.C.; Schwartz, A.V.; Link, T.M. Bone marrow fat composition as a novel imaging biomarker in postmenopausal women with prevalent fragility fractures. $J$. Bone Miner. Res. 2013, 28, 1721-1728. [CrossRef]

78. Grey, A.; Beckley, V.; Doyle, A.; Fenwick, S.; Horne, A.; Gamble, G.; Bolland, M. Pioglitazone increases bone marrow fat in type 2 diabetes: Results from a randomized controlled trial. Eur. J. Endocrinol. 2012, 166, 1087-1091. [CrossRef]

79. Paccou, J.; Hardouin, P.; Cotten, A.; Penel, G.; Cortet, B. The role of bone marrow fat in skeletal health: Usefulness and perspectives for clinicians. J. Clin. Endocrinol. Metab. 2015, 100, 3613-3621. [CrossRef]

80. Iwaniec, U.T.; Turner, R.T. Failure to generate bone marrow adipocytes does not protect mice from ovariectomy-induced osteopenia. Bone 2013, 53, 145-153. [CrossRef]

81. Justesen, J.; Mosekilde, L.; Holmes, M.; Stenderup, K.; Gasser, J.; Mullins, J.J.; Seckl, J.R.; Kassem, M. Mice deficient in 11beta-hydroxysteroid dehydrogenase type 1 lack bone marrow adipocytes, but maintain normal bone formation. Endocrinology 2004, 145, 1916-1925. [CrossRef] [PubMed]

82. Qaseem, A.; Forciea, M.A.; McLean, R.M.; Denberg, T.D. Treatment of low bone density or osteoporosis to prevent fractures in men and women: A clinical practice guideline update from the American College of Physicians. Ann. Intern. Med. 2017, 166, 818-839. [CrossRef] [PubMed]

83. Ambrosi, T.H.; Scialdone, A.; Graja, A.; Gohlke, S.; Jank, A.M.; Bocian, C.; Woelk, L.; Fan, H.; Logan, D.W.; Schürmann, A.; et al. Adipocyte accumulation in the bone marrow during obesity and aging impairs stem cell-based hematopoietic and bone regeneration. Cell Stem Cell 2017, 20,771-784. [CrossRef] [PubMed] 
84. Duque, G.; Rivas, D. Alendronate has an anabolic effect on bone through the differentiation of mesenchymal stem cells. J. Bone Miner. Res. 2007, 10, 1603-1611. [CrossRef] [PubMed]

85. Duque, G.; Li, W.; Adams, M.; Xu, S.; Phipps, R. Effects of risedronate on bone marrow adipocytes in postmenopausal women. Osteoporos. Int. 2011, 22, 1547-1553. [CrossRef] [PubMed]

86. Wilson, C. Bone: Risedronate and marrow adiposity. Nat. Rev. Endocrinol. 2010, 6, 597. [PubMed]

87. Yang, Y.; Luo, X.; Xie, X.; Yan, F.; Chen, G.; Zhao, W.; Jiang, Z.; Fang, C.; Shen, J. Influences of teriparatide administration on marrow fat content in postmenopausal osteopenic women using MR spectroscopy. Climacteric 2016, 19, 285-291. [CrossRef]

(C) 2020 by the authors. Licensee MDPI, Basel, Switzerland. This article is an open access article distributed under the terms and conditions of the Creative Commons Attribution (CC BY) license (http://creativecommons.org/licenses/by/4.0/). 